\title{
Wnt-Responsive Lgr5-Expressing Stem Cells Are Hair Cell Progenitors in the Cochlea
}

\author{
Fuxin Shi, ${ }^{1,2}$ Judith S. Kempfle, ${ }^{1,2}$ and Albert S. B. Edge ${ }^{1,2,3}$ \\ ${ }^{1}$ Department of Otology and Laryngology, Harvard Medical School, Boston, Massachusetts $02115,{ }^{2}$ Eaton-Peabody Laboratory, Massachusetts Eye and Ear \\ Infirmary, Boston, Massachusetts 02114, and ${ }^{3}$ Program in Speech and Hearing Bioscience and Technology, Division of Health Science and Technology, \\ Harvard \& MIT, Cambridge, Massachusetts 02139
}

Auditory hair cells are surrounded on their basolateral aspects by supporting cells, and these two cell types together constitute the sensory epithelium of the organ of Corti, which is the hearing apparatus of the ear. We show here that Lgr5, a marker for adult stem cells, was expressed in a subset of supporting cells in the newborn and adult murine cochlea. Lgr5-expressing supporting cells, sorted by flow cytometry and cultured in a single-cell suspension, compared with unsorted cells, displayed an enhanced capacity for self-renewing neurosphere formation in response to Wnt and were converted to hair cells at a higher ( $>10$-fold) rate. The greater differentiation of hair cells in the neurosphere assay showed that Lgr5-positive cells had the capacity to act as cochlear progenitor cells, and lineage tracing confirmed that Lgr5-expressing cells accounted for the cells that formed neurospheres and differentiated to hair cells. The responsiveness to Wnt of cells with a capacity for division and sensory cell formation suggests a potential route to new hair cell generation in the adult cochlea.

\section{Introduction}

Cochlear supporting cells surround the base and lateral surfaces of hair cells and have many of the characteristics of glia, including expression of markers such as GFAP and S100, and a biological role in glutamate transport and provision of neurotrophic support (Takumi et al., 1997; Beattie et al., 2002; Rámirez-Camacho et al., 2006). Supporting cells act as precursors for hair cells in lower vertebrates during hair cell regeneration (BerminghamMcDonogh and Rubel, 2003; Ma et al., 2008). Supporting cells in mammals do not replace hair cells when the inner ear is damaged (Warchol, 2011). This lack of regeneration has been attributed in part to lack of proliferation and to the complex organization of the cochlear sensory epithelium, comprising the organ of Corti in mammals, compared with the hearing organs in fish and birds (Edge and Chen, 2008; Warchol, 2011). The supporting cells express a number of markers that are normal markers of neural stem cells, including Sox2, GLAST (glutamate aspartate transporter), and Musashi (Sakakibara et al., 1996; Okano et al., 2002; Sakaguchi et al., 2004; Oesterle et al., 2008; Kuwabara et al., 2009; Li et al., 2009). Although they exit the cell cycle in late embryogenesis, supporting cells have been shown to divide and differentiate to hair cells if isolated and placed in culture at or around the time of birth (White et al., 2006). Cochlear cells isolated from the newborn organ of Corti give rise to self-renewing neurospheres

Received March 4, 2012; revised May 22, 2012; accepted May 24, 2012.

Author contributions: F.S., J.S.K., and A.S.B.E. designed research; F.S. and J.S.K. performed research; F.S., J.S.K., and A.S.B.E. analyzed data; F.S. and A.S.B.E. wrote the paper.

This work was supported by grants from the National Institute on Deafness and 0ther Communicative Disorders (R01 DC007174, P30 DC05209, and R03 DC010270) and by a Wiggins Fellowship in Inner Ear Biology.

Correspondence should be addressed to Albert S. B. Edge, Eaton-Peabody Laboratory, Massachusetts Eye and Ear Infirmary, 243 Charles Street, Boston, MA 02114. E-mail: albert_edge@meei.harvard.edu.

DOI:10.1523/JNEUROSCI.1064-12.2012

Copyright $\odot 2012$ the authors $\quad 0270-6474 / 12 / 329639-10 \$ 15.00 / 0$ that have the capacity to differentiate to the various cell types of the ear (Oshima et al., 2007; Martinez-Monedero et al., 2008). However, there has been little information available about the origin of cells that give rise to these neurospheres or the differential expression of genes that distinguish supporting cells.

In a previous study, we found that Wnt signaling controlled the expression of Atoh1, which is a key developmental gene in intestinal epithelium and inner ear (Shi et al., 2010). We have found in this study that leucine-rich repeat-containing, G-protein-coupled receptor, Lgr5, is expressed in the cochlea, where we find it restricted to a few types of supporting cells. Lgr5 is a receptor for R-spondins (de Lau et al., 2011) that activate the frizzled-Lrp5/6 complex in conjunction with Wnt and is a marker for adult stem cells in the colon and small intestine (Barker et al., 2007). We have used this marker for the isolation of cells from the organ of Corti that display the capacity to form neurospheres and to become hair cells. Lgr5positive cells but not Lgr5-negative cells differentiated to hair cells, indicating that they were hair cell progenitors.

\section{Materials and Methods}

Animals. Sox2-GFP (Eminli et al., 2008) mice were provided by Konrad Hochedlinger (Harvard Medical School, Boston, MA). Atoh1-nGFP mice (Lumpkin et al., 2003) were provided by Jane Johnson (University of Texas Southwestern Medical Center, Dallas, TX). Mice containing an EGFP-IRES-CreERT2 "knock-in" allele at the Lgr5 locus (Barker et al., 2007) (referred to as Lgr5-GFP or Lgr5-CreER) were obtained from Jackson Labs (Stock 008875). Rosa26-tdTomato reporter mice, which harbor a loxP-flanked STOP cassette in front of a red fluorescent protein variant (tdTomato) at the Rosa26 locus (Madisen et al., 2010), were obtained from Jackson Labs (Stock 007914). All mouse experiments were approved by the Institutional Animal Care and Use Committee of the Massachusetts Eye and Ear Infirmary.

Purification of cochlear cells by flow cytometry. Cochlear tissue was dissected from 4-5 mouse cochleae at postnatal day 1 (P1) or P2 by separation of the organ of Corti from the lateral wall, spiral ganglion, and 
Reissner's membrane. The tissue was trypsinized at $37^{\circ} \mathrm{C}$ for $11 \mathrm{~min}$ and mechanically dissociated in PBS with 2\% fetal bovine serum (FBS, Invitrogen), DNase (10 U/ml, Qiagen), and EDTA ( $2 \mathrm{~mm}$, Sigma). The cells were filtered through a cell strainer ( $40 \mu \mathrm{m}$ diameter) before sorting. Hair cells were stained with FM1-43FX ( $5 \mu \mathrm{g} / \mathrm{ml}$, Invitrogen) for $5 \mathrm{~min}$ at room temperature and washed 3 times with PBS before dissociation. The dissociated cells were sorted on a BD Biosciences FACSAria using the channels for GFP or FM1-43, and both positive and negative fractions were collected. Purity of the sorted cells was assessed by immunostaining and by quantitative reverse transcription (RT)-PCR.

Quantitative RT-PCR. Total RNA was extracted from cells sorted by flow cytometry with the RNeasy Mini Kit (Qiagen) according to the manufacturer's instructions. For reverse transcription, SuperScript II (Invitrogen) was used with random hexamers. The reverse transcription conditions were $25^{\circ} \mathrm{C}$ for $10 \mathrm{~min}$ followed by $37^{\circ} \mathrm{C}$ for $60 \mathrm{~min}$. The reaction was terminated at $95^{\circ} \mathrm{C}$ for $5 \mathrm{~min}$. The $\mathrm{cDNAs}$ were mixed with TaqMan Gene Expression Master Mix (Applied Biosystems) and primers according to the manufacturer's instructions. Samples were analyzed in 96 wells in triplicate by quantitative PCR (Applied Biosystems 7900HT), and PCR thermal cycling conditions were as follows: initial denaturation at $95^{\circ} \mathrm{C}$ for $2 \mathrm{~min}$, denaturation at $95^{\circ} \mathrm{C}$ for $15 \mathrm{~s}$, and annealing/extension at $60^{\circ} \mathrm{C}$ for $1 \mathrm{~min}$ for 45 cycles. Conditions were kept constant for each primer. Gene expression was calculated relative to $18 \mathrm{~S}$ RNA, and the amount of cDNA applied was adjusted so that the Ct value for 18S RNA was between 10 and 13 .

Culture of sorted cells. Purified cells $\left(2000 / \mathrm{cm}^{2}\right)$ from cell sorting were plated on a laminin-coated dish and cultured for $10 \mathrm{~d}$ in DMEM/F12 with 2\% B27, 1\% N2, EGF (20 ng/ml, Millipore Bioscience Research Reagents), bFGF (10 ng/ml, NIH), IGF-1 (50 ng/ml, Millipore Bioscience Research Reagents), and heparan sulfate ( $50 \mathrm{ng} / \mathrm{ml}$, Sigma). Cells that had not attached were removed $1 \mathrm{~d}$ after plating. To label dividing cells, $\mathrm{BrdU}(20 \mu \mathrm{g} / \mathrm{ml}$, Sigma) was added to the culture medium. The cells were fixed and stained for BrdU and hair cell markers after $10 \mathrm{~d}$ of culture.

Inner ear neurosphere formation and differentiation. Dissected or flowsorted cochlear cells were cultured to form neurospheres in ultra low attachment dishes (Costar) at a density of 2000 cells/ml for $5 \mathrm{~d}$ in DMEM/F12 medium (Invitrogen) with 1\% N2 and 2\% B27, EGF, bFGF, IGF-1, and heparan sulfate. For clonal analysis the dissected cochlear cells were cultured in 96 well Petri dishes (USA Scientific) at a density of 1 cell/well for $5 \mathrm{~d}$ in the same medium. The neurospheres were collected every $5 \mathrm{~d}$, mechanically dissociated with a 25 gauge needle (BD Labware), and reseeded in fresh medium. For differentiation, neurospheres were plated on a laminin-coated dish and cultured for $5 \mathrm{~d}$ in DMEM/F12. To label dividing cells, $\operatorname{BrdU}(20 \mu \mathrm{g} / \mathrm{ml}$, Sigma) was included in the culture medium. Cells were analyzed for hair cell and supporting cell markers.

Thermolysin $(0.5 \mathrm{mg} / \mathrm{ml})$ was applied to cochlear tissue for $30 \mathrm{~min}$ at $37^{\circ} \mathrm{C}$ to separate sensory epithelium and mesenchymal tissue, which were then microdissected (Saffer et al., 1996; Zheng et al., 1997). The separation was assessed by immunostaining for hair cell and supporting cell markers. Single cells were isolated and cultured separately to form neurospheres.

For osteogenic differentiation (Jaiswal et al., 1997), neurospheres were plated and cultured for $10 \mathrm{~d}$ in DMEM/10\% FBS with BMP4 $(10 \mathrm{ng} / \mathrm{ml}$, Millipore Bioscience Research Reagents), $50 \mu \mathrm{g} / \mathrm{ml}$ ascorbic acid, $100 \mathrm{~nm}$ dexamethasone, $10 \mathrm{~mm} \beta$-glycerol phosphate, $100 \mathrm{U} / \mathrm{ml}$ penicillin, 1000 $\mathrm{U} / \mathrm{ml}$ streptomycin, and $0.2 \%$ fungizone antimycoticin. The cells were fixed and stained for collagen II.

Lineage tracing of $L g r 5^{\text {pos }}$ cells. To trace the fate of Lgr5-expressing cells, we made Lgr5-CreER/Rosa26-tdTomato, double-positive mice from a cross between homozygous Rosa26-tdTomato and heterozygous Lgr5CreER mice. The nursing mother was injected intraperitoneally with tamoxifen $(250 \mathrm{mg} / \mathrm{kg}$ body weight $)$ on days 1 and 2 after delivery to activate Cre in the pups, and neurospheres were made at P2 and differentiated for $10 \mathrm{~d}$ to follow Lgr5-expressing cells. The cells were analyzed for tdTomato expression and hair cell markers.

To determine the fate of Lgr5-positive progenitor cells, third generation neurospheres from double-positive pups (P2) were administered tamoxifen $(15 \mathrm{~nm})$ for $5 \mathrm{~d}$ just before differentiation, and the expression of tdTomato and hair cell markers was analyzed in the differentiated cells.
To trace Lgr $5^{\text {pos }}$ cochlear progenitors during development, tamoxifen $(250 \mathrm{mg} / \mathrm{kg}$ body weight $)$ was given to the pregnant female at embryonic day 12.5 (E12.5) and the cochlea from double-positive mice was analyzed at E17.5 (tdTomato expression and hair cell and supporting cell markers).

Wnt treatment of inner ear neurospheres. Cells isolated from the organ of Corti of mice at P3 were cultured in suspension for $5 \mathrm{~d}$ to form neurospheres in DMEM/F12 with or without addition of Wnt3a (20 $\mathrm{ng} / \mathrm{ml}$, R\&D Systems), R-spondin1 (200 ng/ml, R\&D Systems), or dickkopf1 (DKK1) (100 ng/ml, R\&D Systems). Neurospheres were collected, mechanically dissociated, and cultured for the second generation in DMEM/12 with EGF, IGF, FGF, and heparan sulfate. Neurospheres were counted at passaging from the first to the second generation.

Neurospheres from Atoh1-nGFP sensory epithelium were infected with empty adenovirus or adenovirus containing $\beta$-catenin or GFP $(9 \times$ $10^{7}$ viral particles) for $16 \mathrm{~h}$ after seeding $\left(10^{6}\right.$ cells/well $)$ in $100 \mu \mathrm{l}$ of Opti-MEM. Cells positive for Atoh1, myosin VIIa, and DAPI were counted after $5 \mathrm{~d}$. The efficiency of viral transduction based on GFP incorporation was $70 \%$ in the plated neurospheres and $20 \%$ in the floating neurospheres. The adenovirus vectors were a generous gift from Galapagos B.V.; Michiels et al., 2002).

Histology and immunostaining. Antibodies used in this study were myosin VIIa (1:800, Proteus Biomedical), myosin VIIa (1:100; Developmental Studies Hybridoma Bank), Sox2 (1:500; Santa Cruz Biotechnology), espin (1:200; Transduction Labs), parvalbumin 3 ( 1:1000; courtesy of Stefan Heller, Stanford University School of Medicine, Stanford, CA), Prox1 (1:200; Millipore Bioscience Research Reagents), p2 ${ }^{\text {Kip1 }}$ (1:200, NeoMarkers), islet1 (1:100; Developmental Studies Hybridoma Bank), BrdU (1:100; ABD Serotec), GFP (1:1000; Invitrogen), $\beta$-III-tubulin (1:500, Covance) collagen type II (1:100, Millipore Bioscience Research Reagents), nestin (1:100, Developmental Studies Hybridoma Bank), CD105 (1:500, BD PharMingen) and Sca1 (1: 500, BD PharMingen). Species-specific Alexa Fluor-conjugated secondary antibodies were used for detection (1:500; Invitrogen).

\section{Results}

\section{Lgr5 marked a subset of supporting cells}

We assessed expression of Lgr5, a marker for adult stem cells in the intestine and hair follicles (Barker and Clevers, 2010; Sato et al., 2011), in the mouse organ of Corti, consisting of the sensory hair cells and supporting cells that surround them (Fig. 1A). Whereas all supporting cells were stained for Sox2, Lgr5 expression at birth was seen in $4-5$ cells in the greater epithelial ridge, inner border cells, inner pillar cells, and the third row of Deiter's cells (Fig. 1B), using Lgr5-GFP mice (GFP under the control of the Lgr5locus). Identification of the subset of supporting cells labeled for Lgr5 around the inner and outer hair cells (labeled by myosin VIIa) was confirmed as inner but not outer pillar cells by comparison of the Prox1 staining of outer pillar cells and Deiter's cells to the Lgr5 label (Fig. 1C). At P60 the third row of Deiter's cells and the inner pillar cells retained their expression of Lgr5 (Fig. 1D).

\section{Lgr5-positive supporting cells divided and generated hair cells}

We tested whether Lgr5-expressing mammalian supporting cells, which are normally postmitotic at birth but show a limited capacity to act as hair cell progenitors when isolated, had any capacity to divide and differentiate to hair cells. We purified GFPexpressing cells from a Sox2-GFP (Fig. 2A) or Lgr5-GFP (Fig. 2 B) mouse organ of Corti. Sox $2^{\text {pos }}$ and $\operatorname{Lgr} 5^{\text {pos }}$ supporting cells sorted by flow cytometry (Fig. 2C,E) showed no staining for hair cell marker, myosin VIIa (Fig. 2G,H), but displayed an enriched set of supporting cell markers (Fig. 2D,F). Negative sorting for Atoh1 or FM-143 removed hair cells from Lgr5 ${ }^{\text {pos }}$ supporting cells but did not significantly change the percentage of hair cells resulting from differentiation (data not shown).

Sox $2^{\text {pos }}$ supporting cells formed colonies (3-5 cells) that expressed hair cell marker, myosin VIIa, after a $10 \mathrm{~d}$ culture (Fig. 


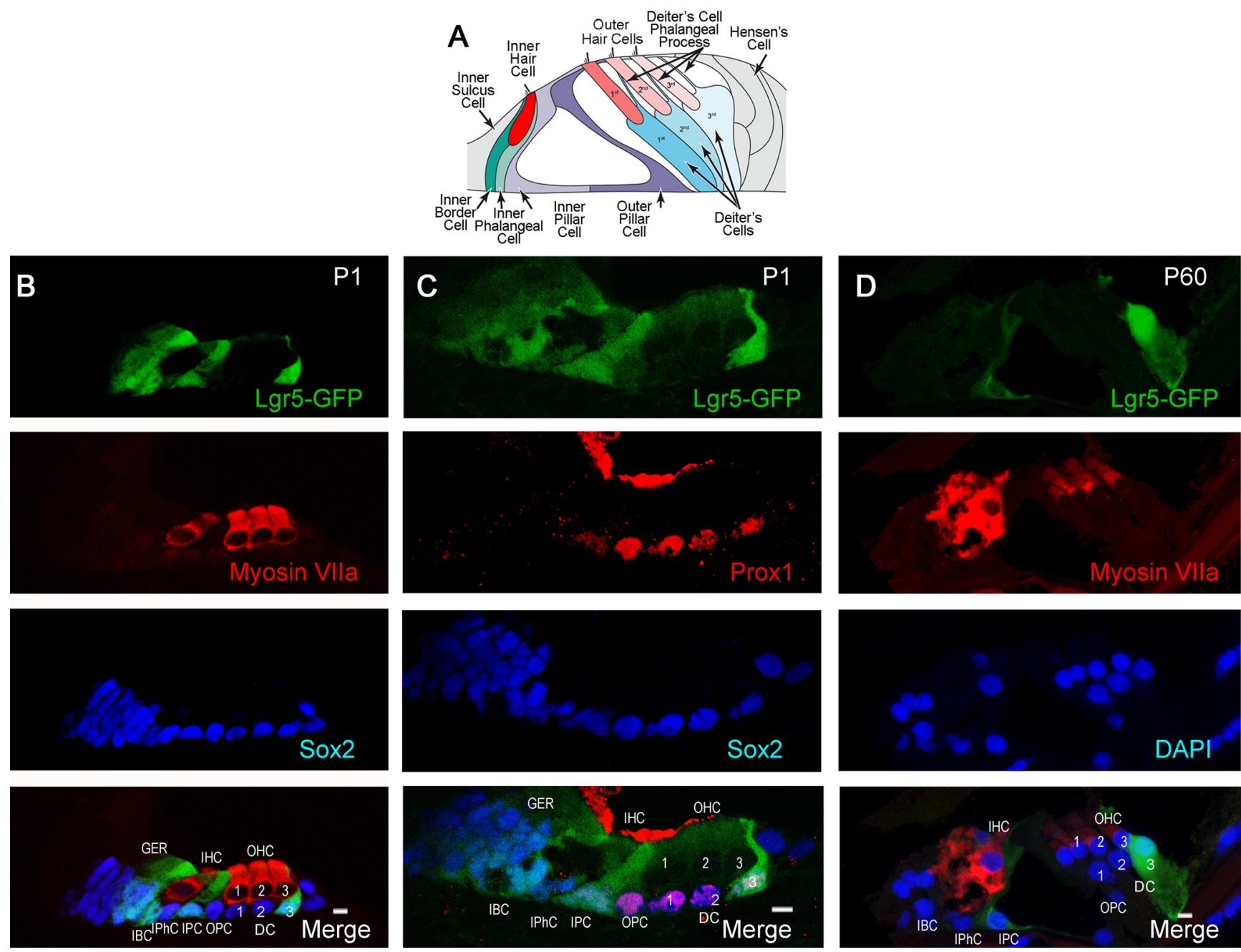

Figure 1. Lgr5 expression in a subset of supporting cells.A, Schematic shows arrangement of sensory epithelial cells in the adult organ of Corti (adapted from Thiers et al., 2008). B, AtP1, Lgr5 (Lgr5-GFP, first panel) was expressed in the greater epithelial ridge, inner border cells, inner pillar cells, and the third row of Deiter's cells. Hair cells were stained with a myosin VIla antibody (second panel). All supporting cells and cells in the greater epithelial ridge were stained with an antibody to Sox2 (third panel). The merged image is shown in the bottom panel (Merge). C, Compared with Lgr5 (first panel), Prox1 was expressed in outer pillar cells and Deiter's cells (second panel). Third panel shows the expression of Sox2 for comparison. D. At P60 the third row of Deiter's cells and the inner pillar cells retained expression of Lgr5 (first panel). Hair cells were stained with an antibody to myosin VIla (second panel). Nuclei were counterstained with DAPI (third panel). The merged image is shown in the bottom panel (Merge). IHC, Inner hair cells; OHC-1, 2,3, outer hair cells; IPC, inner pillar cells; IPhC, inner phalangeal cells; IBC, inner border cells; DC-1, 2, 3, Deiter's cells; OPC, outer pillar cells; GER, greater epithelial ridge.

$2 I)$. None of the cells in the Sox $2^{\text {neg }}$ fraction expressed myosin VIIa (Fig. 2I). Lgr5 ${ }^{\text {pos }}$ supporting cells formed similar-sized colonies containing an indistinguishable percentage (33.5\% vs $32.5 \%$ ) of myosin VIIa-positive cells/colony (Fig. $2 J$ ), but a higher percentage of the colonies $(68.2 \pm 13.6 \%$ vs $8.2 \pm 3.1 \%$; $p<0.05)$ contained myosin VIIa-positive cells. Lgr ${ }^{\text {pos }}$ cells proliferated as shown by BrdU staining (Fig. 2J) and some of the myosin VIIa-staining cells were costained for BrdU. Lgr $5^{\text {neg }}$ cells had a similar rate of BrdU incorporation but no myosin VIIa-positive cells were observed. Myosin VIIa-positive cells costained for parvalbumin 3 (Fig. $2 \mathrm{~K}$ ) and espin (Fig. 2L), a marker for hair cell stereocilia (Sekerková et al., 2004). Thus, the hair cell-containing colonies that grew from cells sorted for Sox 2 and Lgr5 had a similar percentage of hair cells, but a significantly higher percentage of hair cell-containing colonies was obtained from the Lgr5 ${ }^{\text {pos }}$ cells (Fig. $2 M$ ).

\section{Hair cell differentiation by Lgr5-positive} cochlear neurospheres

To assess the potential of Lgr $5^{\text {pos }}$ cells as hair cell progenitors that can expand and differentiate, we tested the sorted cells from cochlear sensory epithelium in a neurosphere assay. Sox $2^{\text {pos }}$ and Sox $2^{\text {neg }}$ cells, as well as Lgr5 $5^{\text {pos }}$ and Lgr $5^{\text {neg }}$ cells, proliferated and formed neurospheres that incorporated BrdU (Fig. $3 A, B, J$ ). The neurospheres from Sox $2^{\text {pos }}$ and Lgr $5^{\text {pos }}$ cells retained high levels of Lgr5 and Sox 2 expression but were negative for myosin VIIa expression (Fig. $3 C, D$ ). Upon differentiation the Sox ${ }^{\text {pos }}$ neurospheres gave rise to myosin VIIa-positive cells at a fourfold higher rate than those from cells depleted of hair cells by negative sorting for Atoh1 (Fig. 3E,K); Sox2 expression was decreased after differentiation. Myosin VIIapositive cells were not found after differentiation of neurospheres made from Sox ${ }^{\text {neg }}$ cells (Fig. $3 E$ ). Differentiation of Lgr5 ${ }^{\text {pos }}$ compared with Sox2-sorted or Atoh1 negatively sorted neurospheres generated myosin VIIa-expressing cells (Fig. $3 F$ ) at a greater than tenfold higher rate (Fig. $3 K ; p<0.05$ ). In contrast, Lgr5 ${ }^{\text {neg }}$ neurospheres did not give rise to hair cells (Fig. $3 F$ ). Lgr5 expression was lost in the myosin VIIa-expressing cells but was retained in cells surrounding the myosin VIIa-positive cells along with Sox2 (Fig. $3 G$ ). The myosin VIIa-positive cells costained for parvalbumin 3 (Fig. 3 H; myosin VIIa and parvalbumin 3 have been found in physiologically active hair cells differentiated from neurospheres; Oshima et al., 2007). Cells that did not differentiate and remained Lgr5positive continued to express supporting cell marker, islet1 (Fig. 3I). 
A
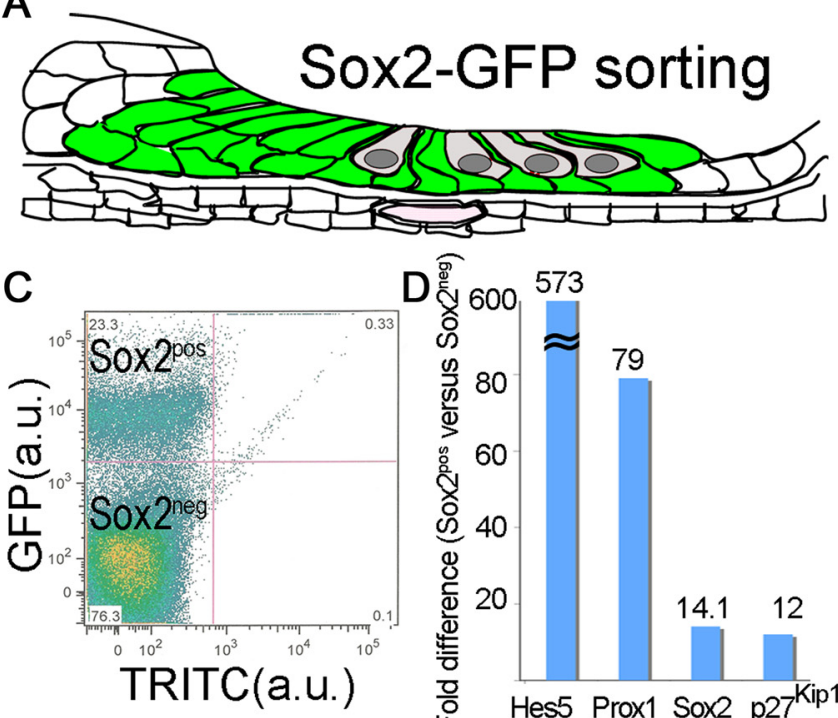

G

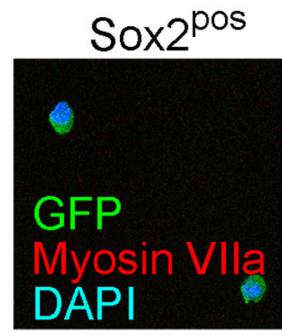

D总 600

573
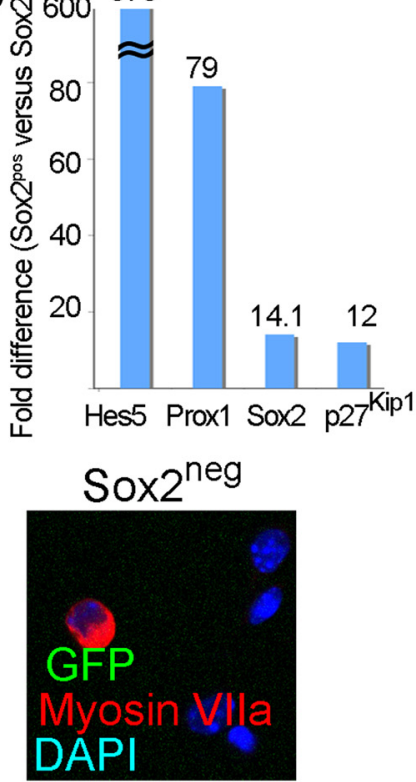

I
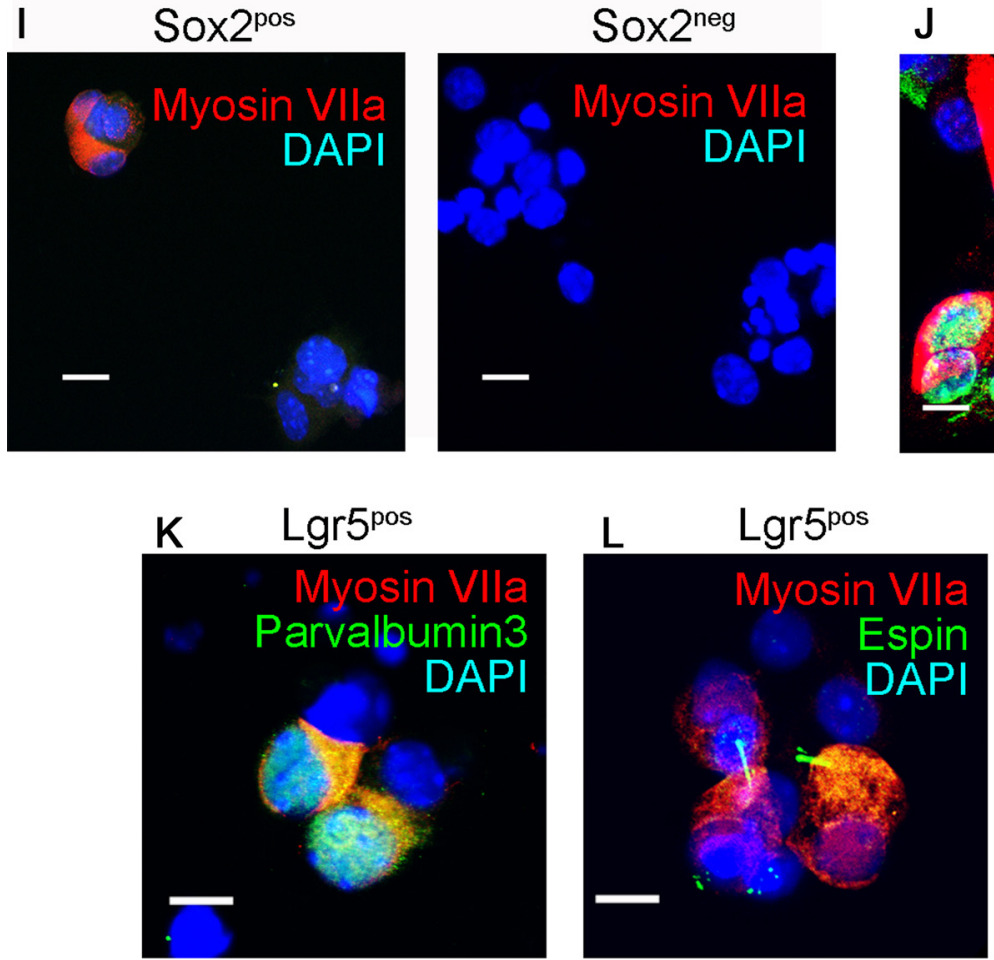
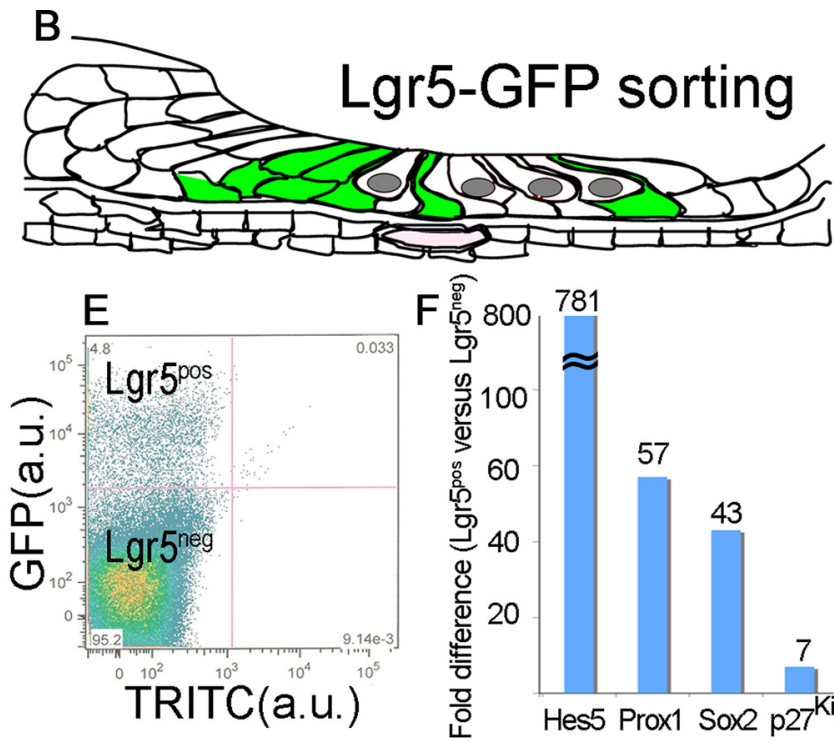

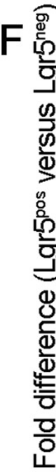
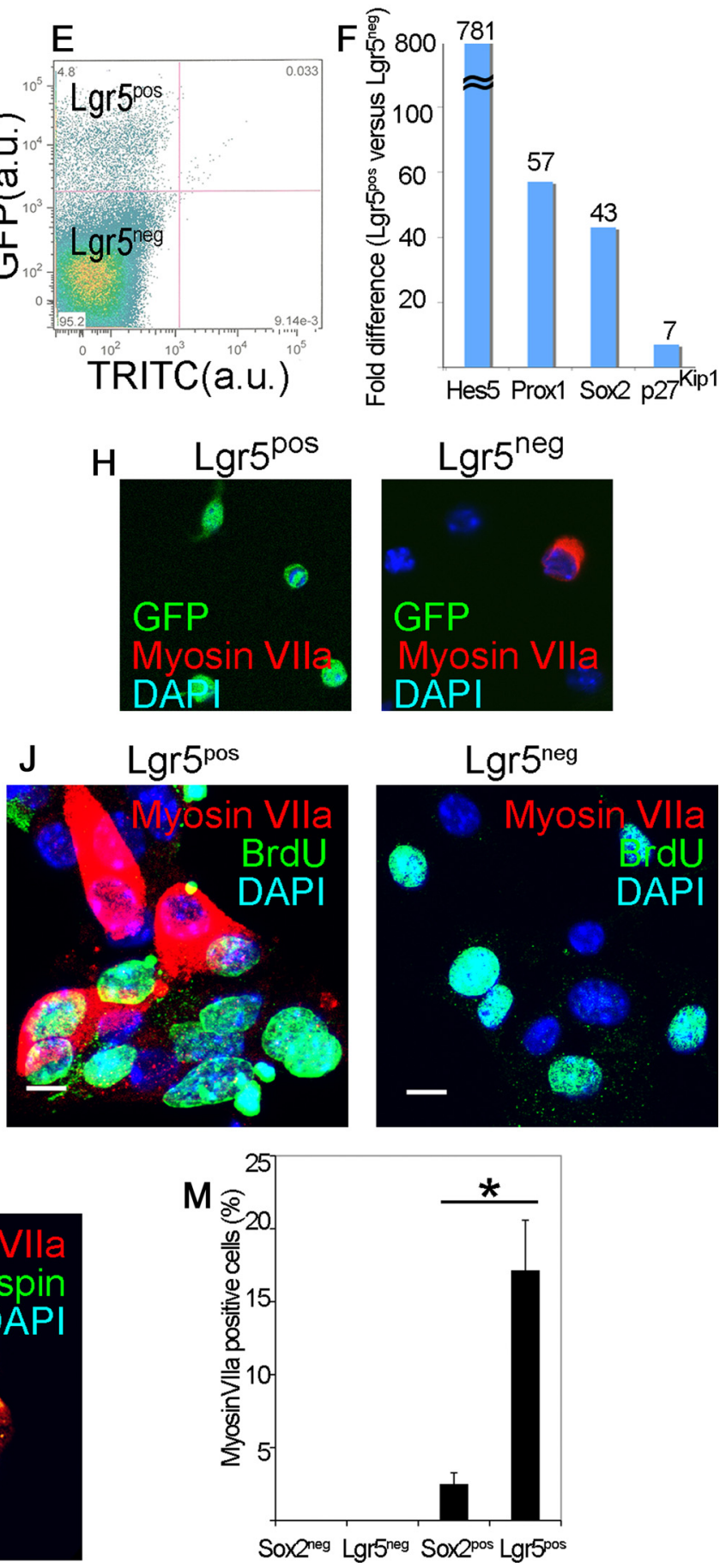

Figure 2. Lgr5-positive supporting cells acted as hair cell progenitors in vitro. A, All supporting cells and greater epithelial ridge are labeled in the newborn Sox2-GFP mouse. B, The supporting cells and greater epithelial ridge cells shown in Figure 1 are fluorescent in the newborn Lgr5-GFP mouse. C, Sox2-expressing cells from the organ of Corti were separated by flow cytometry (Sox2 ${ }^{\text {pos }}$ 23.3\%). D, An enrichment in supporting cell markers in the Sox ${ }^{\text {pos }}$ fraction was seen by quantitative RT-PCR (mean, $n=2$ ). $\boldsymbol{E}$, Lgr5-expressing cells from the organ of Corti were separated by flow cytometry (Lgr5 $\left.{ }^{\text {pos }}, 4.8 \%\right) . F$, An enrichment in supporting cell markers in the Lgr ${ }^{\text {pos }}$ fraction was seen by quantitative RT-PCR (mean, $\left.n=2\right) . \boldsymbol{G}$, The Sox $2^{\text {neg }}$ but not the Sox $2^{\text {pos }}$ fraction contained myosin VIla-positive cells. Nuclei were stained with DAPI. $\boldsymbol{H}$, The Lgr5 ${ }^{\text {pos }}$ fraction was free of myosin VIlla-positive cells which were in the L Lr5 ${ }^{\text {neg }}$ fraction. $\boldsymbol{I}$, Myosin VIlla-positive cells were produced after $10 \mathrm{~d}$ of culture of Sox ${ }^{\text {pos }}$ but not Sox ${ }^{\text {neg }}$ cells. J, Lgr $5^{\text {pos }}$ but not Lgr ${ }^{\text {neg }}$ cells gave rise to myosin Vlla-positive cells after $10 \mathrm{~d}$ in culture, but had similar rates of BrdU incorporation. $\boldsymbol{K}$, Differentiation of Lgr5 ${ }^{\text {pos }}$ cells resulted in myosin VIlla costaining with parvalbumin 3. L, Espin staining in the myosin VIla-positive cells. $\boldsymbol{M}$, The myosin VIlla staining in cultured Lgr5-sorted cells was 6.9 times higher than for Sox2-sorted cells. Means \pm SEM are shown, $n=3$. 

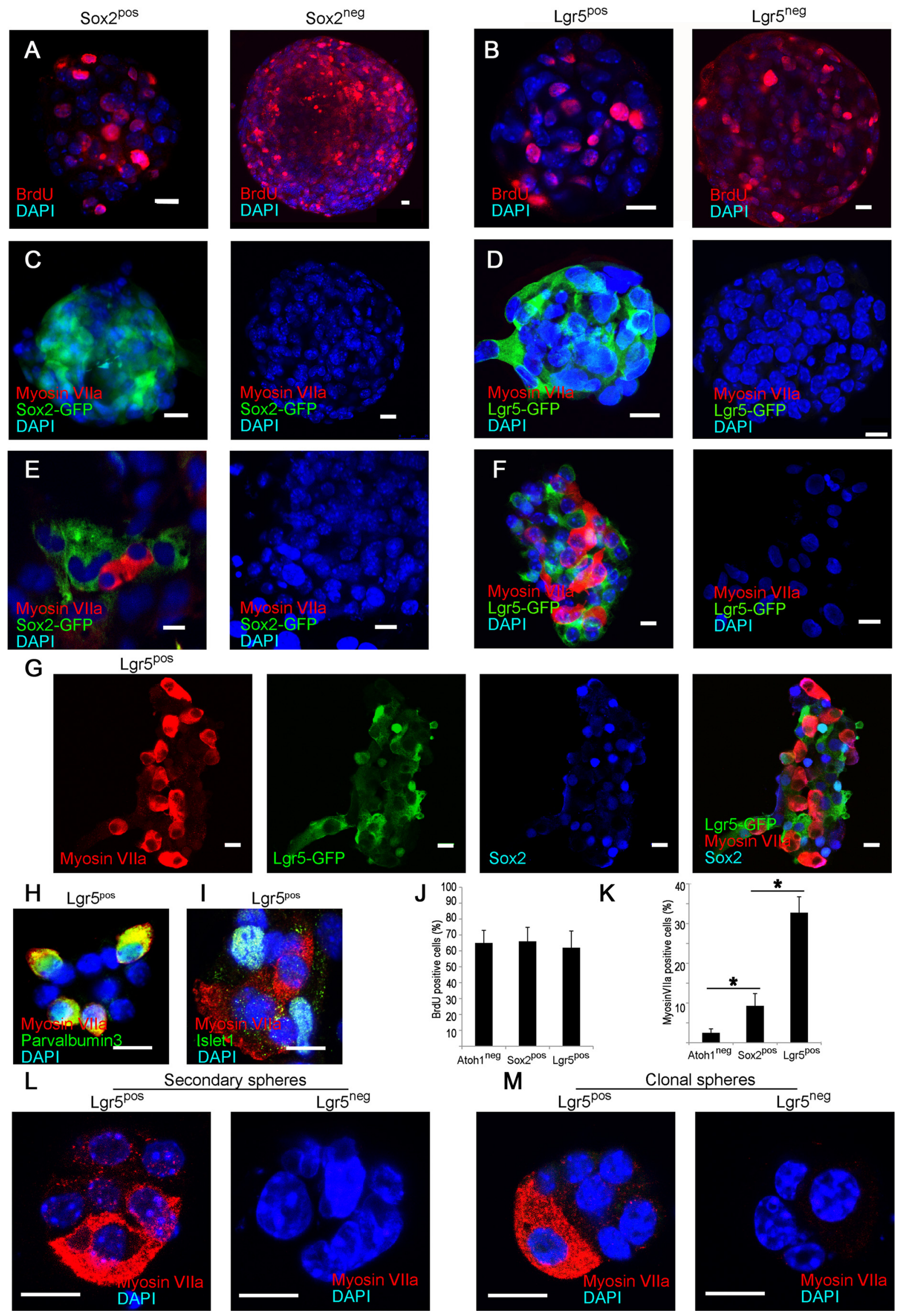

Figure 3. Hair cell generation only from Lgr5-expressing neurospheres. $\boldsymbol{A}$, Neurospheres formed by the Sox ${ }^{\text {pos }}$ and Sox $2^{\text {neg }}$ fractions incorporated BrdU. $\boldsymbol{B}$, Sorted Lgr5 ${ }^{\text {pos }}$ and Lgr $5^{\text {neg }}$ cells formed neurospheres that incorporated BrdU. C, Neurospheres formed by the Sox $2^{\text {pos }}$ and Sox $2^{\text {neg }}$ fractions did not contain hair cells (Myosin VIla). D, Neurospheres made (Figure legend continues.) 
Secondary neurospheres made by sorting $\operatorname{Lgr} 5^{\text {pos }}$ cells from primary neurospheres maintained the capacity to differentiate into hair cells (Fig. $3 L$ ) and dissociated cells from cochlear sensory epithelium formed clonal neurospheres in a 96-well plate assay (average of 2 positive wells/plate, $n=12$ plates). The neurospheres from Lgr $5^{\text {pos }}$ but not Lgr $5^{\text {neg }}$ cells gave rise to hair cells upon differentiation (Fig. 3M).

\section{Lgr $5^{\text {pos }}$ cells gave rise to hair cell lineages in vivo and in vitro}

To ask whether hair cells were derived from Lgr5-expressing supporting cells, we crossed Lgr5-CreER mice with reporter mice in which a floxed STOP cassette prevents transcription of a downstream red fluorescent protein (tdTomato). When neonatal mice were administered one dose of tamoxifen at P1 and the cochlea was examined at $24 \mathrm{~h}$, reporter expression was observed in supporting cells that were Lgr5-positive based on GFP (data not shown). Hair cells from cochlear neurospheres obtained at $\mathrm{P} 2$ from mice administered tamoxifen at $\mathrm{P} 1$, after passaging to the third generation and differentiation, were double-positive for myosin VIIa and tdTomato, showing a derivation from Lgr5-expressing supporting cells (Fig. 4A). Of the tdTomato-positive cells, $12 \%$ were positive for myosin VIIa ( $n=3,100$ neurospheres counted). Lgr5-Cre did not label all hair cells in these cultures, presumably due to incomplete labeling of reporters by this Cre mouse (Barker et al., 2007).

We next administered tamoxifen to neurospheres from Lgr5CreER reporter mice at the third generation. Upon differentiation, cells positive for hair cell markers were also positive for tdTomato (Fig. $4 B$, Lgr5 ${ }^{\text {pos }}$ cells), showing that Lgr5-positive progenitors in the neurospheres generated hair cells.

To ask whether progenitors that expressed Lgr5 during development of the cochlea gave rise to the sensory epithelium, we labeled Lgr5expressing cells during development. We administered one dose of tamoxifen at E12.5 (before hair cell differentiation) and analyzed the inner ear at E17.5 (at which point differentiation of hair cells is complete). At E12.5, Lgr5 was expressed in the same progenitors as Sox2, throughout the prosensory area (Fig. 4C). Cre recombination-induced reporter activity observed $24 \mathrm{~h}$ after tamoxifen treatment indicated that Lgr5 was expressed in the Sox2-expressing prosensory domains (data not shown). By E17.5, both hair cells (myosin VIIa; Fig. 4D) and supporting cells (Sox2; Fig. 4E) expressed tdTomato, indicating derivation from Lgr5-expressing progenitors. Not all hair cells were stained, again suggesting that the Cre did not label all cells expressing Lgr5.

Lgr5-positive neurospheres were responsive to Wnt signaling Sorted Lgr5 ${ }^{\text {pos }}$ cells formed smaller more homogenous neurospheres than Lgr ${ }^{\text {neg }}$ cells (Fig. 5A). Multiple passages revealed that neurospheres from Lgr $5^{\text {pos }}$ cells expanded more rapidly than neurospheres from Lgr $5^{\text {neg }}$ cells (Fig. 5B).

\footnotetext{
(Figure legend continued.) from sorted Lgr $5^{\text {pos }}$ and Lgr ${ }^{\text {neg }}$ cells showed no labeling for myosin VIlla. $\boldsymbol{E}$, Myosin VIlla-positive cells were observed upon differentiation of neurospheres made from the Sox2 ${ }^{\text {pos }}$ cells but not the Sox $2^{\text {neg }}$ cells. $\boldsymbol{F}$, After differentiation, neurospheres made from Lgr $5^{\text {pos }}$ cells generated myosin VIla-positive cells. No hair cells were observed upon differentiation of neurospheres made from the Lgr5 ${ }^{\text {neg }}$ cells. G, Differentiated Lgr5 ${ }^{\text {pos }}$ neurospheres retained Lgr5 and Sox2 surrounding the myosin VIlla-positive cells that lost expression of Lgr 5 . $\boldsymbol{H}$, Myosin VIlla-staining cells from Lgr ${ }^{\text {pos }}$ neurospheres costained for parvalbumin $3 . I$, Cells surrounding the myosin Vlla-positive cells expressed islet1. J, Neurospheres made from Atoh1 (negatively sorted), or Sox2 or Lgr5 (positively sorted) cells had similar rates of cell division. $\boldsymbol{K}$, Increasing capacity for hair cell differentiation was found in neurospheres made from Atoh1, Sox2 or Lgr5-sorted cells. Means \pm SEM are shown, $n=3$. Scale bars, $10 \mu \mathrm{m}$. $L$, Secondary neurospheres made by sorting Lgr5 ${ }^{\text {pos }}$ cells differentiated into myosin VIla-positive hair cells. No hair cells were observed after differentiation of secondary neurospheres from Lgr5 ${ }^{\text {neg }}$ cells. $M$, Clonal neurospheres from single L Lr ${ }^{\text {pos }}$ but not from single Lgr $5^{\text {neg }}$ cells from cochlear sensory epithelium gave rise to hair cells upon differentiation.
}

Wnt3a addition increased the expansion of neurospheres from Lgr $5^{\text {pos }}$ cells at passaging from the first to the second generation and, conversely, blocking Wnt signaling by addition of DKK1, a Wnt antagonist, decreased neurosphere expansion sixfold (Fig. 5C,D). R-spondin1, a ligand for Lgr5, also increased the number of neurospheres, acting synergistically with Wnt3a (Fig. 5D).

Wnt signaling has been implicated in acquisition of cell fate in addition to expansion (Ootani et al., 2009; Qu et al., 2010), and transcription factor Atoh1, which is necessary for hair cell differentiation in the embryonic inner ear (Bermingham et al., 1999), is activated by $\beta$-catenin (Shi et al., 2010). Adenovirus-mediated expression of $\beta$-catenin increased the percentage of Atoh1positive cells after differentiation of neurospheres (Fig. $5 E$ ), and $\sim 50 \%$ of the Atoh1-positive cells expressed myosin VIIa (Fig. $5 F$ ), showing that $\mathrm{Wnt} / \beta$-catenin signaling influenced progenitor cell differentiation to hair cells.

\section{Mesenchymal tissue lacked hair cell progenitors}

To test for other possible sources of hair cell progenitors in the cochlea, we separated mesenchymal tissue from sensory epithelium (illustrated in Fig. 6A). Both tissues gave rise to spheres, but sensory epithelial spheres $(45 \pm 8 \mu \mathrm{m})$ expressed nestin, Sox2, and Lgr5, but not CD105 and Scall (Fig. 6B,C), and mesenchymal spheres $(150 \pm 12 \mu \mathrm{m})$ expressed nestin and mesenchymal markers, CD105 and Scal1, but not prosensory markers, Sox 2 or Lgr5 (Fig. $6 B, D$ ). Spheres from both tissues expanded and incorporated BrdU, but unlike the sensory epithelial spheres (Fig. 6E), the mesenchymal spheres cultured under differentiating conditions differentiated into neurons and collagen II-expressing chondrocytes but did not give rise to hair cells (Fig. 6F).

\section{Discussion}

Although mammalian hair cells and supporting cells are postmitotic and the mammalian inner ear does not regenerate spontaneously, supporting cells in the mammalian organ of Corti share markers and signaling pathways with lower vertebrate supporting cells, which act as progenitors to hair cells. Our results show that in the mouse cochlea, Lgr5, which was expressed in the prosensory cells in the embryo and was gradually restricted to a specific subset of supporting cells, identified cells with progenitor cell properties. Compared with p27 Kip (Chen and Segil, 1999) and Prox1 (Bermingham-McDonogh et al., 2006), which are expressed only in early postnatal mice, and Sox2, which is widely expressed in supporting cells, Lgr5 was limited in its expression, suggesting that the set of supporting cells that possessed properties of progenitors was restricted as in lower vertebrates, where a small subset of supporting cells replace damaged hair cells by proliferation followed by transdifferentiation (Stone et al., 1999).

Lgr5 was first described as a stem cell marker for intestinal epithelial cells and has since been demonstrated as a marker of the stem cell compartment in the stomach and hair follicles (Barker et al., 2007, 2009; Jaks et al., 2008; Fuchs, 2009; Barker and Clevers, 2010). Lgr5 has been identified as a receptor for R-spondins, which activate the Wnt signaling pathway through an interaction between Lgr5 and frizzled-Lrp5/6. Lgr5 cells were precursors for all cells in the intestinal crypts (Barker et al., 2007). Deletion of Lgr5 in the gut resulted in rapid and complete loss of intestinal crypts, a similar phenotype to the complete loss of Wnt signaling (de Lau et al., 2011). Expression of Wnt-agonist, R-spondin1, expanded Lgr5-positive cell populations in crypts (Barker et al., 2009; Ootani et al., 2009).

Lgr5-positive cells in the cochlea share characteristics of cycling stem cells in the intestinal epithelium, but remain dormant. There is no detectable proliferation of postnatal cells in the sensory epithe- 

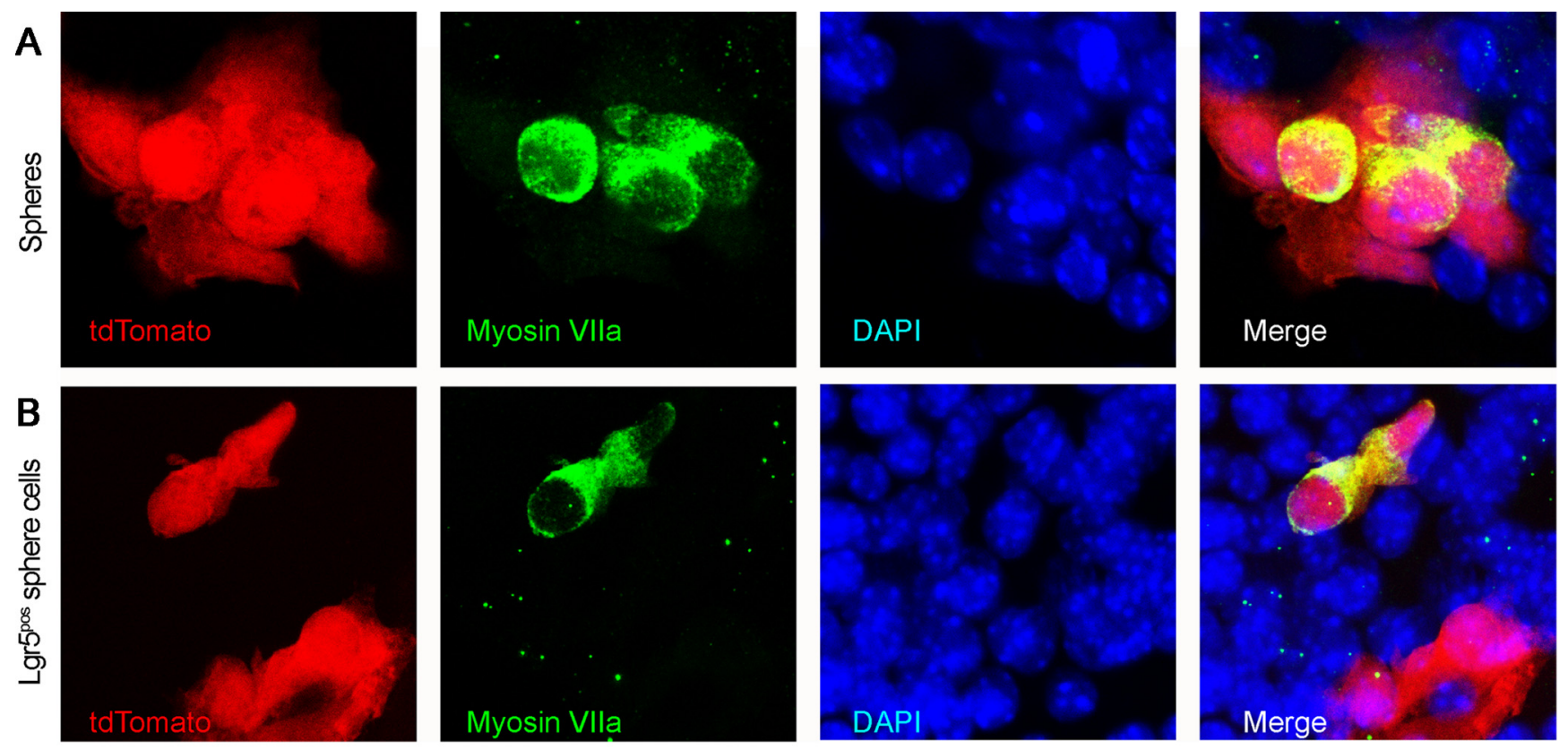

C
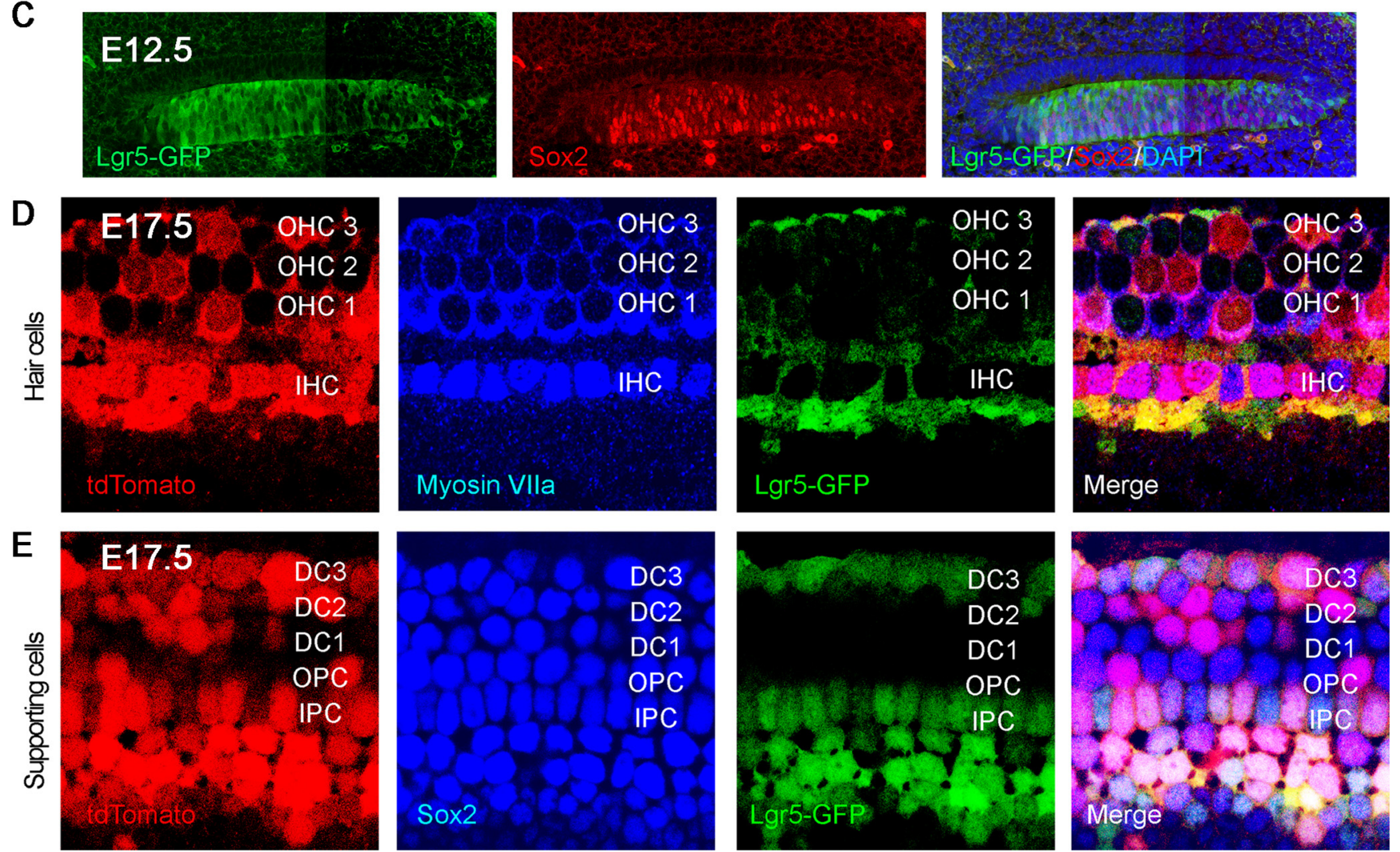

Figure 4. Lgr5-positive cells were progenitors for hair cells in vitro and in vivo. A, Neurospheres were obtained from Lgr5-CreER mice crossed to tdTomato reporter mice that had been treated with tamoxifen at P1 to label Lgr5-expressing cells. The label for tdTomato in hair cells that were positive for myosin Vlla indicated a derivation from Lgr5-expressing supporting cells. $\boldsymbol{B}$, When tamoxifen was added to third generation neurospheres from Lgr5-CreER reporter mice, labeling by tdTomato was observed in cells positive for hair cell markers, indicating derivation of hair cells from Lgr5-positive cells in the spheres. C, At E12.5, Lgr5 (Lgr5-GFP, left) colocalized with Sox2-positive progenitor cells in the cochlear duct (middle). D, Hair cell generation was traced back to Lgr5-positive progenitor cells using a tdTomato lineage tag (E12-E17). E, Supporting cells beyond the restricted Lgr5-GFP-positive subset were tdTomato-positive.

lium, although the cells, when isolated postnatally, form neurospheres that differentiate to hair cells in vitro (Oshima et al., 2007; Martinez-Monedero et al., 2008; Jeon et al., 2011). Isolated supporting cells reenter the cell cycle and generate new hair cells (White et al., 2006), but it has been unclear what cells could proliferate and possessed properties of stem cells (Oshima et al., 2007; MartinezMonedero et al., 2008). Spheres formed from inner ear cells are heterogeneous, and spheres generated from sensory epithelium, but not from mesenchymal tissue, expressed markers of sensory neural progenitors and had the capacity to generate hair cells. The neurospheres that gave rise to hair cells originated from supporting cells expressing Lgr5. Purified postmitotic supporting cells from both Lgr5 ${ }^{\text {pos }}$ and Lgr5 ${ }^{\text {neg }}$ fractions formed neurospheres, but the Lgr5 ${ }^{\text {pos }}$ cells showed enhanced neurosphere formation, and Lgr5-expressing 
A
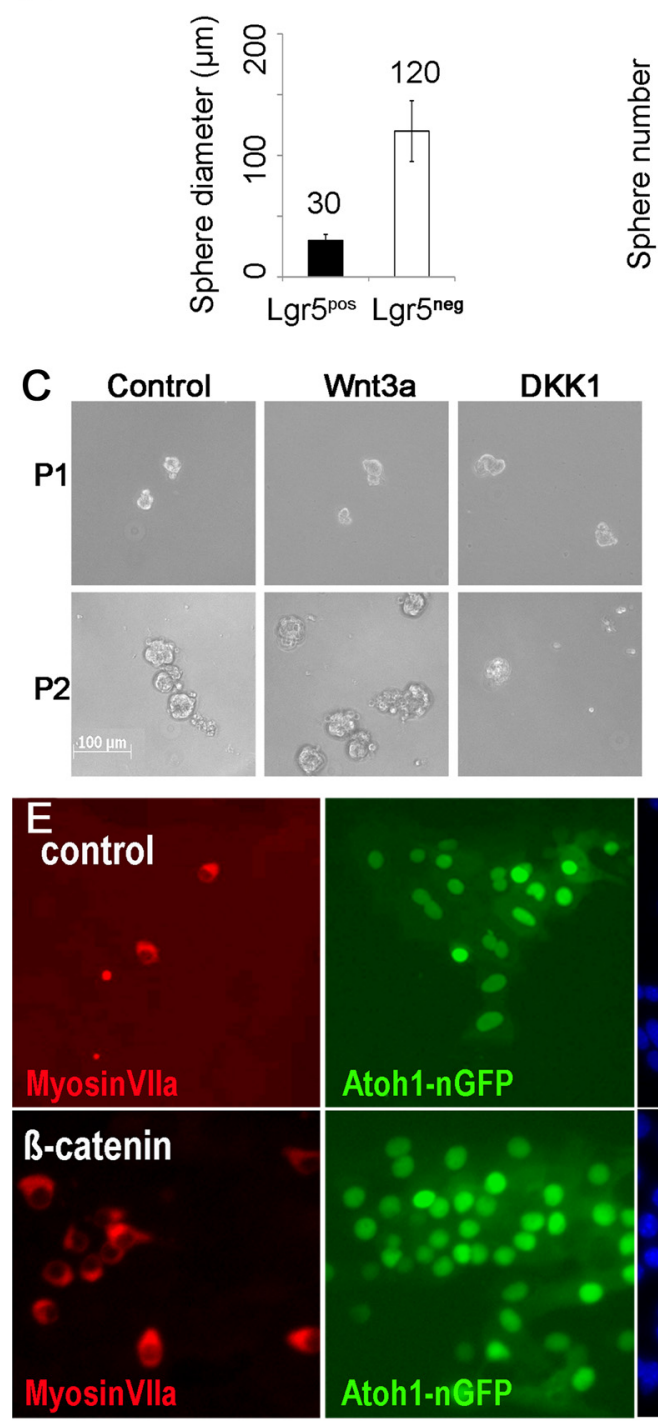
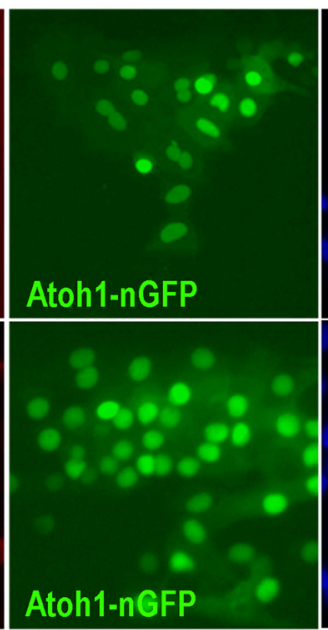

B

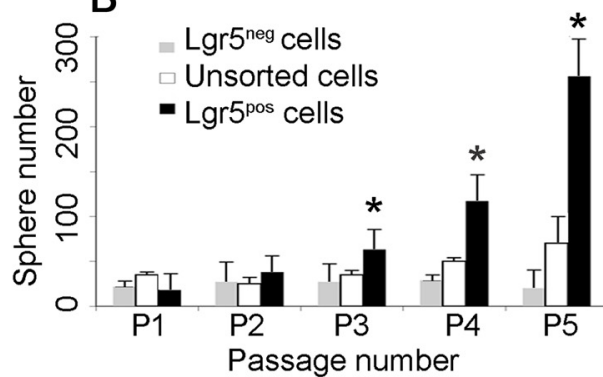

F
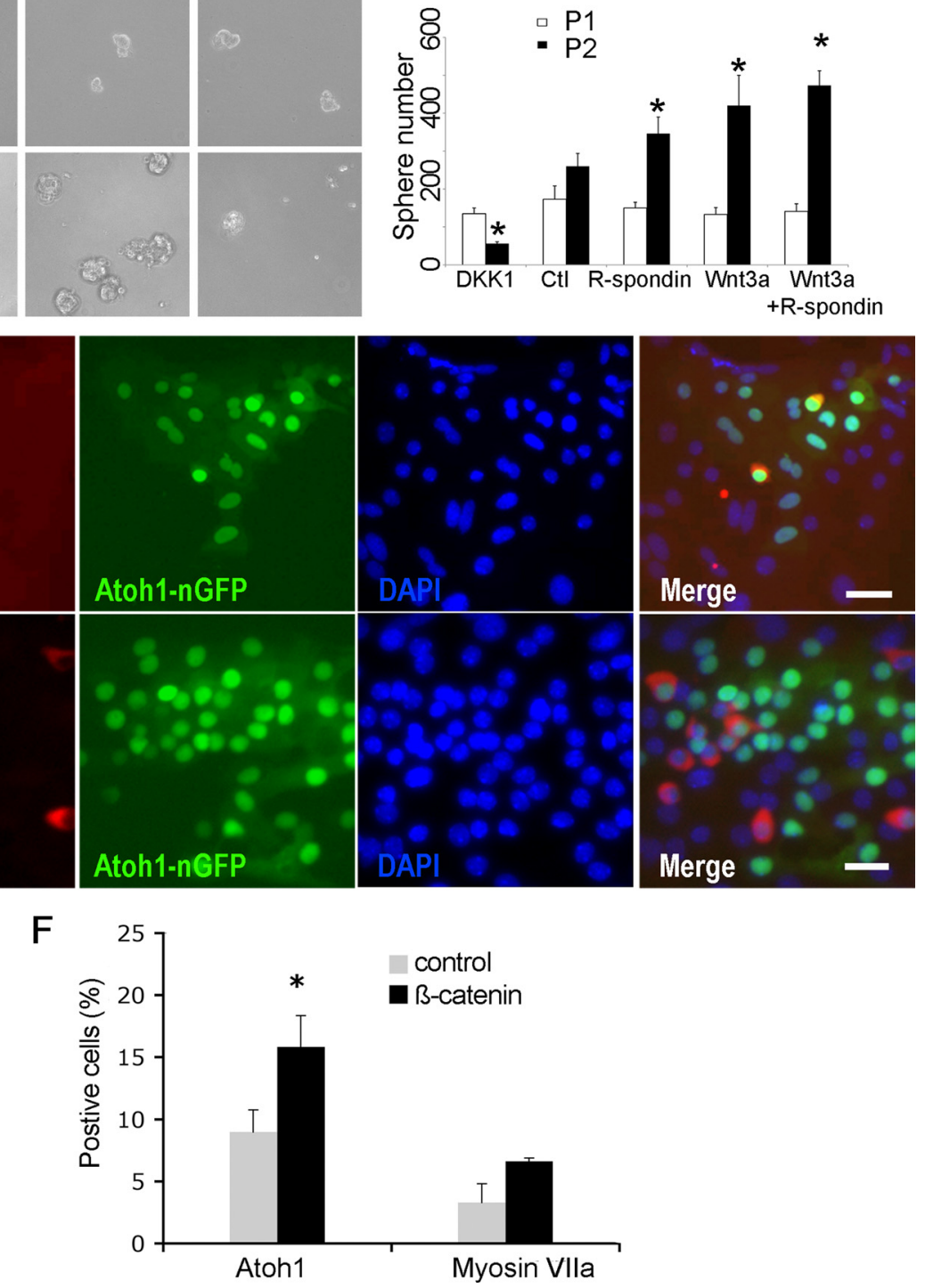

Figure 5. Cochlear neurospheres respond to Wnt/ $\beta$-catenin signaling. $A$, Neurospheres from Lgr ${ }^{\text {pos }}$ compared with Lgr ${ }^{\text {neg }}$ neurospheres cells were smaller and more homogenous. $\boldsymbol{B}$, Neurospheres from Lgr $5^{\text {pos }}$ compared with Lgr ${ }^{\text {neg }}$ cells had a significantly higher rate of expansion (indicated by asterisk) upon multiple passages $(p<0.05, n=3)$. C, Neurospheres are shown at passaging from the first to the second generation in the absence of other factors (Control) or in the presence of either Wnt3a-conditioned medium (Wnt3a) or Dickkopf1 (DKK1). D, Cells treated with R-spondin1, Wnt3a, or Wnt3a and R-spondin 1 generated significantly more neurospheres, and treatment with DKK1 significantly reduced the number of neurospheres $(p<0.05, n=3)$. $\boldsymbol{E}$, Transduction of cochlear neurospheres with adenovirus containing the $\beta$-catenin gene ( $\beta$-catenin) gave rise to more Atoh1 (green)- and myosin VIlla (red)-positive cells than an empty adenoviral vector (Control). Nuclei were stained with DAPI (blue). $\boldsymbol{F}$, Quantification of Atoh1 and myosin VIla-positive cells ( $n=3,5000$ cells counted). Scale bar, $20 \mu \mathrm{m}$.

cells differentiated into hair cells at a significantly higher rate (mean of $31 \%$, Fig. 3) than unfractionated cells. Lgr5 ${ }^{\text {neg }}$ cells including those that were Sox $2^{\text {pos }}$ did not give rise to hair cells. As in the maturation of intestinal epithelial stem cells to transit amplifying cells (Snippert et al., 2009), Lgr5 expression was lost upon differentiation, suggesting that it acts as a marker for the stem cell compart- ment in the ear as well. The increased yield of hair cells from the inner ear neurospheres enriched for Lgr5 is consistent with the cells acting as hair cell progenitors. Our lineage tracing results did not allow us to account for all new hair cells, and, while we believe that this was due to incomplete labeling of Lgr5-positive cells by the Cre line used (Barker et al., 2007), we cannot rule out the possibility that other cells 
A

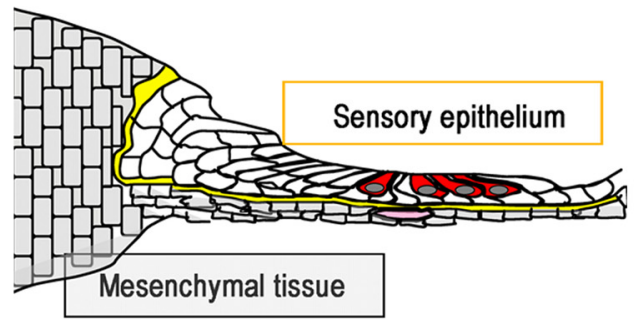

B

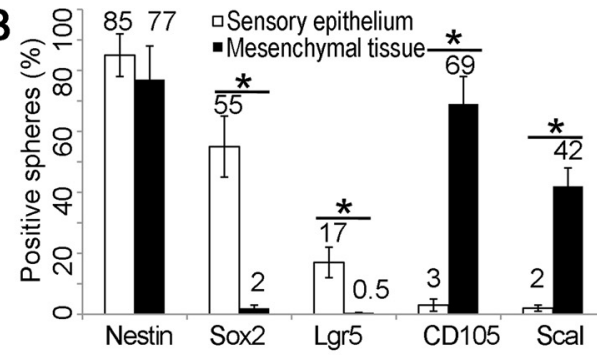

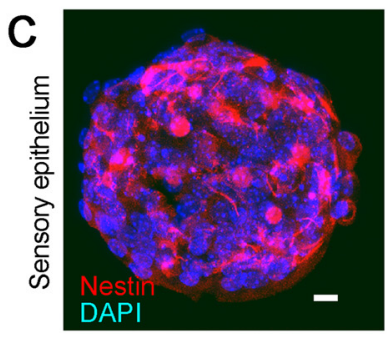
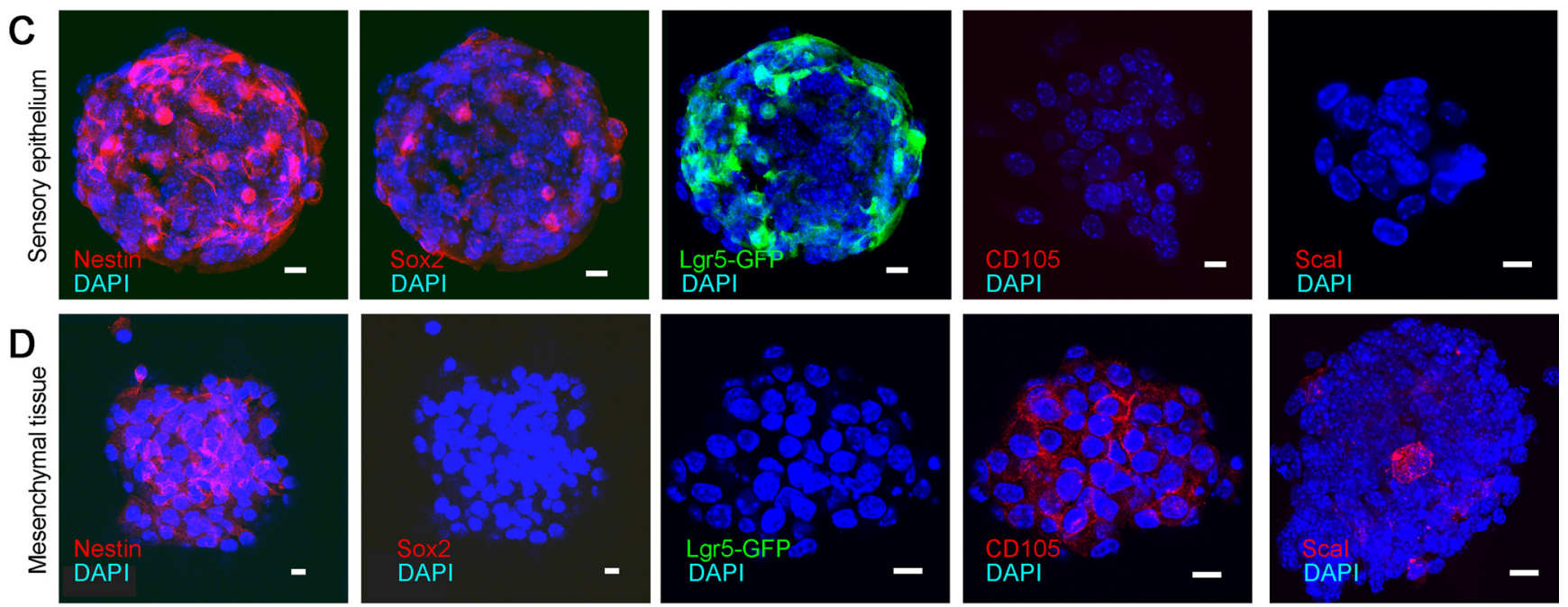

$E$
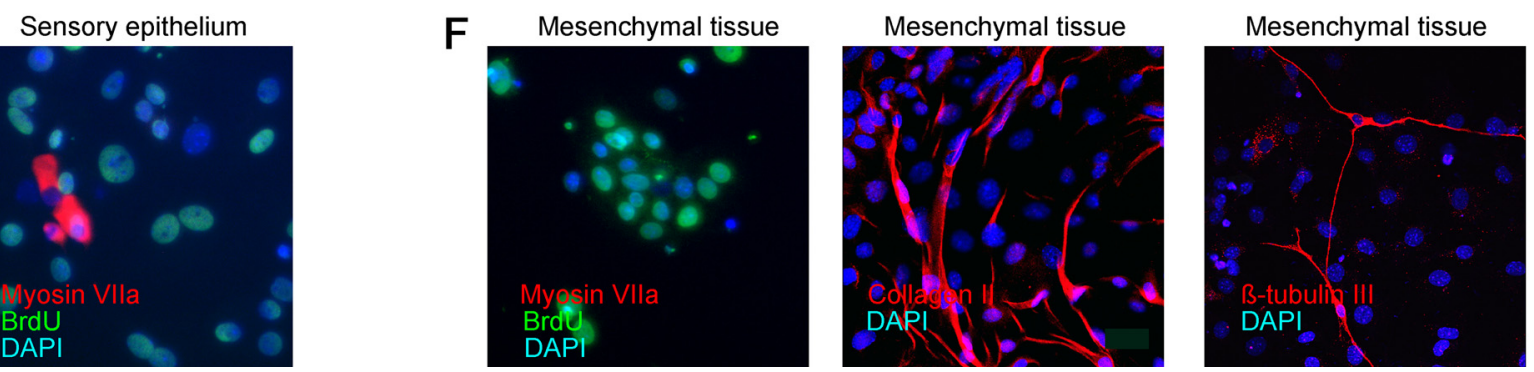

Figure 6. Lack of progenitors for hair cells in mesenchymal tissue. $\boldsymbol{A}$, Separation of sensory epithelium from mesenchymal tissue after treatment with thermolysin is depicted. $\boldsymbol{B}$, Spheres from sensory epithelium stained for neural stem cell markers and spheres from mesenchyme did not ( 50 spheres counted; $n=3$; asterisk indicates $p<0.05$ ). $C$, Neurospheres produced from sensory epithelial spheres after separation with thermolysin, expressing nestin, prosensory markers, Sox2, and Lgr5, but not mesenchymal markers, CD105 and Sca1. D, Mesenchymal spheres (positive for nestin, CD105 and Sca1) did not express Sox2 or Lgr5. E, Cells from sensory epithelium formed neurospheres that were labeled for BrdU and gave rise to myosin VIla-positive hair cells under differentiating conditions. $\boldsymbol{F}$, When cultured under differentiating conditions, the mesenchymal spheres were labeled for BrdU but did not give rise to cells expressing hair cell markers (Myosin VIla). The mesenchymal cells differentiated into collagen II-positive chondrocytes and $\beta$ III-tubulin-positive neurons.

in the cochlea could have the capacity for differentiation to hair cells after neurosphere formation.

Lgr5 expression correlates with Wnt activity and we tested differentiating neurospheres for responsiveness to Wnt mediator $\beta$-catenin because its effects were more potent than Wnt ligands in reporter assays. Overexpression of $\beta$-catenin caused an increase in hair cell marker-positive cells (Shi et al., 2010). Because of low adenoviral-mediated $\beta$-catenin overexpression in the floating neurospheres, we evaluated their response to Wnt3a and R-spondin1 directly. Neurosphere expansion was enhanced, providing further evidence for the progenitor role of the Lgr5-positive cells. Thus, as in neural progenitor cells in the CNS (Chenn and Walsh, 2002; Adachi et al., 2007; Kuwabara et al., 2009; Freese et al., 2010), Wnt signaling plays a dual role in inner ear stem cells, stimulating both expansion and differentiation. We plan to further dissect the roles of Wnt and Lgr5 in expansion and differentiation in cochlear cells by protein mediators and genetic activation of the Wnt pathway in future studies.
Our ability to isolate inner ear stem cells and identify them in vivo using Lgr5 is an important step toward understanding their biology. The difficulty in isolating progenitor cells from the adult cochlea precluded their investigation in the current study. Hair cells and supporting cells are postmitotic and the mammalian inner ear does not spontaneously regenerate following damage. Supporting cells are capable of giving rise to hair cells after manipulation of embryonic or newborn mammalian inner ears by, for example, overexpressing Atoh1, and Lgr5-positive cells of the greater epithelial ridge can be converted to hair cells (Zheng and Gao, 2000). We have found that $\beta$-catenin stimulated the transcription factor, Atohl (Shi et al., 2010), and Wnt could thus increase differentiation of cells that require Atoh1. Lgr5 served as a marker for supporting cells that displayed some characteristics of stem cells. The Lgr5-expressing cells may have the potential to regenerate hair cells and could provide a new route to replacement of these cells, a sought-after goal for treatment of hearing loss, which is most commonly caused by loss of hair cells in humans. 


\section{References}

Adachi K, Mirzadeh Z, Sakaguchi M, Yamashita T, Nikolcheva T, Gotoh Y, Peltz G, Gong L, Kawase T, Alvarez-Buylla A, Okano H, Sawamoto K (2007) Beta-catenin signaling promotes proliferation of progenitor cells in the adult mouse subventricular zone. Stem Cells 25:2827-2836.

Barker N, Clevers H (2010) Leucine-rich repeat-containing G-proteincoupled receptors as markers of adult stem cells. Gastroenterology 138:1681-1696.

Barker N, van Es JH, Kuipers J, Kujala P, van den Born M, Cozijnsen M, Haegebarth A, Korving J, Begthel H, Peters PJ, Clevers H (2007) Identification of stem cells in small intestine and colon by marker gene Lgr5. Nature 449:1003-1007.

Barker N, Ridgway RA, van Es JH, van de Wetering M, Begthel $H$, van den Born M, Danenberg E, Clarke AR, Sansom OJ, Clevers H (2009) Crypt stem cells as the cells-of-origin of intestinal cancer. Nature 457:608-611.

Beattie MS, Harrington AW, Lee R, Kim JY, Boyce SL, Longo FM, Bresnahan JC, Hempstead BL, Yoon SO (2002) ProNGF induces p75-mediated death of oligodendrocytes following spinal cord injury. Neuron 36:375-386.

Bermingham NA, Hassan BA, Price SD, Vollrath MA, Ben-Arie N, Eatock RA, Bellen HJ, Lysakowski A, Zoghbi HY (1999) Mathl: an essential gene for the generation of inner ear hair cells. Science 284:1837-1841.

Bermingham-McDonogh O, Rubel EW (2003) Hair cell regeneration: winging our way towards a sound future. Curr Opin Neurobiol 13:119-126.

Bermingham-McDonogh O, Oesterle EC, Stone JS, Hume CR, Huynh HM, Hayashi T (2006) Expression of Proxl during mouse cochlear development. J Comp Neurol 496:172-186.

Chen P, Segil N (1999) p27(Kip1) links cell proliferation to morphogenesis in the developing organ of Corti. Development 126:1581-1590.

Chenn A, Walsh CA (2002) Regulation of cerebral cortical size by control of cell cycle exit in neural precursors. Science 297:365-369.

de Lau W, Barker N, Low TY, Koo BK, Li VS, Teunissen H, Kujala P, Haegebarth A, Peters PJ, van de Wetering M, Stange DE, van Es JE, Guardavaccaro D, Schasfoort RB, Mohri Y, Nishimori K, Mohammed S, Heck AJ, Clevers H (2011) Lgr5 homologues associate with Wnt receptors and mediate R-spondin signalling. Nature 476:293-297.

Edge AS, Chen ZY (2008) Hair cell regeneration. Curr Opin Neurobiol $18: 377-382$

Eminli S, Utikal J, Arnold K, Jaenisch R, Hochedlinger K (2008) Reprogramming of neural progenitor cells into induced pluripotent stem cells in the absence of exogenous Sox2 expression. Stem Cells 26:2467-2474.

Freese JL, Pino D, Pleasure SJ (2010) Wnt signaling in development and disease. Neurobiol Dis 38:148-153.

Fuchs E (2009) The tortoise and the hair: slow-cycling cells in the stem cell race. Cell 137:811-819.

Jaiswal N, Haynesworth SE, Caplan AI, Bruder SP (1997) Osteogenic differentiation of purified, culture-expanded human mesenchymal stem cells in vitro. J Cell Biochem 64:295-312.

Jaks V, Barker N, Kasper M, van Es JH, Snippert HJ, Clevers H, Toftgård R (2008) Lgr5 marks cycling, yet long-lived, hair follicle stem cells. Nat Genet 40:1291-1299.

Jeon SJ, Fujioka M, Kim SC, Edge ASB (2011) Notch signaling alters sensory or neuronal cell fate specification of inner ear stem cells. J Neurosci 31:8351-8358.

Kuwabara T, Hsieh J, Muotri A, Yeo G, Warashina M, Lie DC, Moore L, Nakashima K, Asashima M, Gage FH (2009) Wnt-mediated activation of NeuroD1 and retro-elements during adult neurogenesis. Nat Neurosci 12:1097-1105.

Li C, Li A, Li M, Xing Y, Chen H, Hu L, Tiozzo C, Anderson S, Taketo MM, Minoo P (2009) Stabilized beta-catenin in lung epithelial cells changes cell fate and leads to tracheal and bronchial polyposis. Dev Biol 334:97-108.

Lumpkin EA, Collisson T, Parab P, Omer-Abdalla A, Haeberle H, Chen P, Doetzlhofer A, White P, Groves A, Segil N, Johnson JE (2003) Math1driven GFP expression in the developing nervous system of transgenic mice. Gene Expr Patterns 3:389-395.

Ma EY, Rubel EW, Raible DW (2008) Notch signaling regulates the extent of hair cell regeneration in the zebrafish lateral line. J Neurosci 28:2261-2273.

Madisen L, Zwingman TA, Sunkin SM, Oh SW, Zariwala HA, Gu H, Ng LL, Palmiter RD, Hawrylycz MJ, Jones AR, Lein ES, Zeng H (2010) A robust and high-throughput Cre reporting and characterization system for the whole mouse brain. Nat Neurosci 13:133-140.

Martinez-Monedero R, Yi E, Oshima K, Glowatzki E, Edge AS (2008) Dif- ferentiation of inner ear stem cells to functional sensory neurons. Dev Neurobiol 68:669-684

Michiels F, van Es H, van Rompaey L, Merchiers P, Francken B, Pittois K, van der Schueren J, Brys R, Vandersmissen J, Beirinckx F, Herman S, Dokic K, Klaassen H, Narinx E, Hagers A, Laenen W, Piest I, Pavliska H, Rombout Y, Langemeijer E, et al. (2002) Arrayed adenoviral expression libraries for functional screening. Nat Biotechnol 20:1154-1157.

Oesterle EC, Campbell S, Taylor RR, Forge A, Hume CR (2008) Sox2 and JAGGED1 expression in normal and drug-damaged adult mouse inner ear. J Assoc Res Otolaryngol 9:65-89.

Okano H, Imai T, Okabe M (2002) Musashi: a translational regulator of cell fate. J Cell Sci 115:1355-1359.

Ootani A, Li X, Sangiorgi E, Ho QT, Ueno H, Toda S, Sugihara H, Fujimoto K, Weissman IL, Capecchi MR, Kuo CJ (2009) Sustained in vitro intestinal epithelial culture within a Wnt-dependent stem cell niche. Nat Med 15:701-706.

Oshima K, Grimm CM, Corrales CE, Senn P, Martinez Monedero R, Géléoc GS, Edge A, Holt JR, Heller S (2007) Differential distribution of stem cells in the auditory and vestibular organs of the inner ear. J Assoc Res Otolaryngol 8:18-31.

Qu Q, Sun G, Li W, Yang S, Ye P, Zhao C, Yu RT, Gage FH, Evans RM, Shi Y (2010) Orphan nuclear receptor TLX activates Wnt/beta-catenin signalling to stimulate neural stem cell proliferation and self-renewal. Nat Cell Biol 12:31-40; sup pp 1-9.

Rámirez-Camacho R, García-Berrocal JR, Trinidad A, González-García JA, Verdaguer JM, Ibáñez A, Rodríguez A, Sanz R (2006) Central role of supporting cells in cochlear homeostasis and pathology. Med Hypotheses 67:550-555.

Saffer LD, Gu R, Corwin JT (1996) An RT-PCR analysis of mRNA for growth factor receptors in damaged and control sensory epithelia of rat utricles. Hear Res 94:14-23.

Sakaguchi H, Yaoi T, Suzuki T, Okano H, Hisa Y, Fushiki S (2004) Spatiotemporal patterns of Musashil expression during inner ear development. Neuroreport 15:997-1001.

Sakakibara S, Imai T, Hamaguchi K, Okabe M, Aruga J, Nakajima K, Yasutomi D, Nagata T, Kurihara Y, Uesugi S, Miyata T, Ogawa M, Mikoshiba K, Okano H (1996) Mouse-Musashi-1, a neural RNA-binding protein highly enriched in the mammalian CNS stem cell. Dev Biol 176:230-242.

Sato T, van Es JH, Snippert HJ, Stange DE, Vries RG, van den Born M, Barker N, Shroyer NF, van de Wetering M, Clevers H (2011) Paneth cells constitute the niche for Lgr5 stem cells in intestinal crypts. Nature 469:415-418.

Sekerková G, Zheng L, Loomis PA, Changyaleket B, Whitlon DS, Mugnaini E, Bartles JR (2004) Espins are multifunctional actin cytoskeletal regulatory proteins in the microvilli of chemosensory and mechanosensory cells. J Neurosci 24:5445-5456.

Shi F, Cheng YF, Wang XL, Edge AS (2010) Beta-catenin up-regulates Atoh1 expression in neural progenitor cells by interaction with an Atoh1 3' enhancer. J Biol Chem 285:392-400.

Snippert HJ, van Es JH, van den Born M, Begthel H, Stange DE, Barker N, Clevers H (2009) Prominin-1/CD133 marks stem cells and early progenitors in mouse small intestine. Gastroenterology 136:2187-2194.e1.

Stone JS, Choi YS, Woolley SM, Yamashita H, Rubel EW (1999) Progenitor cell cycling during hair cell regeneration in the vestibular and auditory epithelia of the chick. J Neurocytol 28:863-876.

Takumi Y, Matsubara A, Danbolt NC, Laake JH, Storm-Mathisen J, Usami S, Shinkawa H, Ottersen OP (1997) Discrete cellular and subcellular localization of glutamine synthetase and the glutamate transporter GLAST in the rat vestibular end organ. Neuroscience 79:1137-1144.

Thiers FA, Nadol JB Jr, Liberman MC (2008) Reciprocal synapses between outer hair cells and their afferent terminals: evidence for a local neural network in the mammalian cochlea. J Assoc Res Otolaryngol 9:477-489.

Warchol ME (2011) Sensory regeneration in the vertebrate inner ear: differences at the levels of cells and species. Hear Res 273:72-79.

White PM, Doetzlhofer A, Lee YS, Groves AK, Segil N (2006) Mammalian cochlear supporting cells can divide and trans-differentiate into hair cells. Nature 441:984-987.

Zheng JL, Gao WQ (2000) Overexpression of Math1 induces robust production of extra hair cells in postnatal rat inner ears. Nat Neurosci 3:580-586

Zheng JL, Helbig C, Gao WQ (1997) Induction of cell proliferation by fibroblast and insulin-like growth factors in pure rat inner ear epithelial cell cultures. J Neurosci 17:216-226. 